\title{
ANGIOLO MAZZONI: LA ESTÉTICA MUSSOLINIANA APLICADA A LA ARQUITECTURA ESTATAL. RELACIONES CON LAS ARTES PLÁSTICAS Y REMINISCENCIAS EN LA ARQUITECTURA DE LA CIUDAD CONTEMPORÁNEA
}

\author{
ANGIOLO MAZZONI: MUSSOLINIAN AESTHETICS APPLIED TO \\ THE STATE ARCHITECTURE. RELATIOSHIPS WITH THE PLASTIC \\ ARTS AND REMINISCENCES IN CONTEMPORARY CITY'S \\ ARCHITECTURE
}

JuAn Agustín ManceBo RocA

Universidad de Castilla- La Mancha

Recibido: 02/10/2019

Aceptado: 01/12/2019

\section{RESUMEN}

Angiolo Mazzoni, arquitecto italiano de entreguerras, estuvo vinculado al futurismo y al Novecento, a partir de una praxis entendida como extensión del régimen político. Su obra más conocida, la Estación Térmica de Santa María Novella, fue un premio de consolación por la polémica de su proyecto de la Estación de Santa María Novella en Florencia (1929). A partir de las reminiscencias futuristas y constructivistas de la Estación Térmica, la obra de Mazzoni adquirió un tono novecentista e incluso metafísico, en la línea de pintores como De Chirico, Carlo Carrà y Mario Sironi. Obras que reflejaban el clima político y cultural como la Colonia Rosa Maltoni Mussolini en Calambrone (1925-26), los edificios postales proyectados entre 1925 y 1935 y sus trabajos para la Ferrovie dello Stato, lo configuran como uno de los arquitectos que trasladaron la estética del fascismo a sus edificaciones, creando una iconografía vinculada al poder político de la Italia mussoliniana. Este artículo se centra en los estilos de Mazzoni, su referencia a los artistas metafísicos, las intervenciones futuristas, así como el 
puente entre estas arquitecturas y las de Aldo Rossi o Massimo Scolari en las que vinculan sus edificios y proyectos a las grandes corporaciones del poder financiero y cultural contemporáneo.

Palabras clave: Futurismo, metafísica, Novecento, estilo fascista.

\begin{abstract}
Angiolo Mazzoni, an Italian architect in the inter-war period, was linked to Futurism and Novecento from a workload that was an extension of the political regime. His most well-known piece, the Thermal Station in Santa Maria Novella was a conso-lation prize that came from the controversy that his project, Santa Maria Novella Station, suscitated in Florence (1929). Based on the Futuristic and Constructivist aspects of the Thermal Station, Mazzonis' work acquired a Novecentist tone, metaphysical even, following painters like De Chirico, Carlo Carra and Mario Sironi. His works were a reflection of the political and cultural landscape, like Calambrone (1925-26), the designs for post offices made between 1925 and 1935, as well as his work for Ferrovie dello Stato. Those projects made him one of the architects that translated fascist aesthetics into its buildings, creating an iconography linked to the political power in Mussolini's Italy. This lecture will be centered around Mazzoni's styles, his relationships with the metaphysical artists, his contributions to Futurist, as well as the links between this architectural style and Aldo Rossi's, or Massimo Scolari's, where the different projects and buildings are related to the big financial and cultural corporations of their time.
\end{abstract}

Keywords: Futurism, metaphysics, Novecento, fascist style. 
Continuando la línea estilística que arrancaba desde el siglo XIX, la cultura italiana de entreguerras estuvo determinada por tendencias artísticas que bascularon entre tradición y modernidad. La búsqueda de un discurso que prefijara el presente, fue una disposición ficticia establecida por la pervivencia del pasado como elemento constituyente de un nuevo orden estético y político. Las reminiscencias del liberty, la influencia centroeuropea, el segundo futurismo discutida etiqueta en la que se replantea toda la historia del movimiento-, novecento y racionalismo, fueron las tendencias que dominaron la ecléctica escena arquitectónica italiana hasta la primera mitad del siglo XX.

Tendencias que, por otra parte, fueron protagonistas del imaginario audiovisual del siglo pasado, que ha revisado los preceptos arquitectónicos como espejo social y cultural. Es paradigmático que los maestros del cine italiano hayan incidido en la estética arquitectónica como elemento simbólico de la repre-sentación del poder en distintos films. Películas como La notte (La noche, Michelangelo Antonioni, 1961), L'ultimo uomo della Terra (El último hombre sobre la Tierra, Ubaldo Ragona, 1964), Il conformista, (El conformista 1970) y Novecento (id., 1976) de Bernardo Bertolucci, Noi donne siamo fatte cosí (Las mujeres somos así, Dino Risi, 1971), 4 mosche di velluto grigio (4 moscas sobre terciopelo gris, Dario Argento, 1971), Amarcord (id., 1973) e Intervista, (id., 1976) de Federico Fellini, I nouvi mostri (iQué viva Italia!, Dino Risi, Mario Monicelli, Ettore Scola, 1977), Un borghese piccolo piccolo (Un bur-gués pequeño, muy pequeño, Mario Monicelli, 1977) o Salò o le 120 giornate di Sodoma, (Saló o los 120 días de Sodoma, Pier Paolo Pasolini, 1975) ejemplifican el reflejo de la iconografía italiana contemporánea a partir de la arquitectura. Una representación, del mismo modo, asociada a los estudios cinematográficos en los que se rodaron la mayoría de esas películas, ya que Cinecittá (1937) fue uno de los grandes proyectos culturales elaborados por Mussolini.

En cuanto a la arquitectura, la concepción de una práctica contemporánea estuvo ineludiblemente ligada a la reevaluación del pasado. El escritor Aldo Palazzeschi (1885-1974), mencionaba con ironía y desencanto evaluando los proyectos de la vanguardia en Italia, que desarrollar un proceso de lo moderno no podía escapar del lastre de su esplendoroso pasado. A este respecto, es necesario rescatar las palabras de Cesare de Seta en 1980 sobre la ficción de la arquitectura metafísica,

Nos interesa subrayar que una arquitectura metafísica no existe, sería presuntuoso buscarla en los años veinte, y sería del todo erróneo reconocerla en las espectrales perspectivas del E42 de Roma, que de metafísico no tienen nada, son topoi formales, solo aparentemente parecidos pero de hecho 
profundamente diferentes; son, por el contrario, la imágenes de un extrañamiento de la arquitectura a merced de un academicismo clasicista pobre, tosco y vanaglorioso, justo al contrario de la contenida, sólida y tersa condición clásica metafísica de las ciudades de Italia, de dechiriquiana memoria ${ }^{1}$.

Más allá de una estética definida, las "imágenes de un extrañamiento" van a definir gran parte de la arquitectura de ese periodo. Se hace necesaria, por lo tanto, la revisión del trabajo como proyectista de Angiolo Mazzoni. Pese a ser un arquitecto considerado menor -aunque Bruno Zevi lo menciona en su Storia dell'architettura moderna, Einaudi, Turín 1950)-, Angiolo Mazzoni Del Grande (1894-1979) fue uno de los más relevantes y prolíficos proyectistas italianos de la primera mitad del pasado siglo. Su obra se desarrolló en Italia entre 1922 y 1944 -posteriormente amplificaría trabajo y docencia en Sudamérica en su impuesto autoexilio tras los años del fascismo-gracias a su plaza de ingeniero jefe de la Ferrovie dello Stato (FS), para la que realizó un sinnúmero de intervenciones que abarcaban las dependencias ferroviarias y postales -entonces unificadas- de las ciudades italianas. La obra mazzoniana conforma la puerta de las estaciones italianas concebidas por un arquitecto del que, fuera de los cenáculos de los especialistas y críticos de ámbito italiano, no se conoce demasiado. Representante de la cultura arquitectónica de entreguerras, su eclecticismo fue un sello en el que convergieron las tendencias europeas dominantes: las vanguardias arquitectónicas del futurismo italiano y el constructivismo soviético; la plástica, a partir de la revisión y adaptación de los presupuestos de la pintura metafísica, y la iniciativa de crear una arquitectura que se adecuara a los postulados del Partido Fascista. La dificultad de lectura de su trabajo viene determinada por sus contradicciones estilísticas, así como sus polémicas adhesiones e inesperados giros ideológicos, vinculados a movimientos y personas que le posibilitarían construir en un periodo en el que era bastante complejo obtener encargos que no tuvieran el apoyo de las instituciones públicas.

Este eclecticismo estuvo inscrito en sus años de aprendizaje. Mazzoni acusó en su formación la influencia secesionista en la relectura de Joseph Maria Olbrich (1867-1908) y Josef Hoffmann (1870-1956) y el tradicionalismo de los años veinte. En 1919 logró el título de ingeniería civil en la Escuela de Ingenieros de Roma, paralelamente a su trabajo como asistente en el estudio de Marcello Piacentini (1881-1960). En 1923 obtuvo el título de Arquitecto en la Facultad de Bolonia. Previamente, en 1921, fue nombrado Inspector de Trabajo de la FS en Milán. En 1924, con la unificación de la Ferrovía y Correos (Poste

1 DE SETA, C. en PORTOGHESI, P., "Arquitectura y pintura metafísicas” en TRIONE, V., El siglo de Giorgio de Chirico. Metafisica y arquitectura, Valencia, Skira, 2007, p. 95. 
e Telegrafie y Ferrovie Statali) se trasladó a la Dirección General en Roma. Su primer proyecto como ingeniero jefe de la FS fue la construcción de la Estación de Brennero (1925-26), comienzo de una prolífica y polémica carrera. Su actividad, hasta 1944, engloba edificios como los de correos Agrigento (1932), Trento (1934) y Pola (1935), así como las estaciones ferroviarias de Bolzano (1927), Trento y Siena (1936), Reggio Calabria y Montecatini, ambas en 1937, y Messina (1939).

Es necesario incidir en el interés de Mazzoni por la concepción integral del edificio en el que convergían sus intereses como ingeniero y arquitecto. Por extensión, le preocupaba el mobiliario y los elementos decorativos que obedecían a funciones instrumentales, siendo uno de los proyectistas italianos que con más empeño evolucionaría hacía una práctica asociada nos solo a la arquitectura, sino también al diseño industrial.

\section{APUNTES PARA UNA ARQUITECTURA METAFÍSICA}

Uno de los momentos esenciales de su carrera fue su aproximación a la cultura plástica de la pintura metafísica, cuya convergencia de racionalismo y dinamismo generaba una serie de espacios estancos en los que, como sucediera en la pintura de Mario Sironi (1885-1961), la dinámica futurista se congelaba en el tiempo y el espacio para estructurar uno de los trabajos arquitectónicos más singulares de Europa.

En este contexto, la Colonia Rosa Maltoni Mussolini en Calambrone, proyectada entre 1925 y 1926 e inaugurada en 1933, deja entrever una profunda influencia metafísica. Las dos icónicas columnas-observatorio establecen un nexo argumental con la serie de torres, La torre (id., 1913), La grande torre (La gran torre, 1915) o las series de metafísica renovada tales como La torre del silenzio (La torre del silencio, 1932) y La torre e il treno (La torre y el tren, 1934) de Giorgio de Chirico o Dopo il tramonto (Tras el anochecer, 1927) del futurista desencantado tras la barbarie bélica y ahora metafísico Carlo Carrà. Situada en la costa entre Tirrenia y Livorno, la Colonia Rosa Maltoni Mussolini fue un proyecto en el que emergió toda la carga del extrañamiento arquitectónico, demostrando que las disciplinas plástica y arquitectónica se disolvían y permeabilizaban, recomponiéndose a partir de espacios complementarios. La edificación rememoraba las estaciones abandonadas dominadas por las sombras y la potencialidad icónica del pintor originario de Bolos.

La coincidencia espacial y la poética alternativa es la que ejemplifica, por otra parte, la relación entre la arquitectura y el juego. La Colonia Rosa Maltoni 
Mussolini se diseñó específicamente como una colonia estival para el disfrute de las familias de los trabajadores de Correos y la Ferrovie dello Stato. Como expone Alfredo Forti,

La magia del Calambrone, triste y gris en su invernal abandono compenetrado, estaba también en el acceso rojo anaranjado de aquellos dados y cilindros esparcidos sobre la playa, estudiados para una confortable acogida para los niños ${ }^{2}$.

Por ello, su estructura hace hincapié en esa especie de juguete gigante que nos refiere a los artefactos metafísicos que emergen en las obras de Alberto Savinio -Andrea de Chirico- (1891-1952), convirtiéndose en parte integrante del conjunto arquitectónico y que rememora los misterios de la existencia presentes desde su formación filosófica junto a su hermano en Alemania- así como el carácter mediterráneo de la creación artística.

Los futuristas, por otra parte, intentaron atribuirse la paternidad de la autoría de la Colonia. El movimiento era muy activo propagandísticamente y se había disuelto, tras las Primera Guerra Mundial, en una serie de grupúsculos de provincia que respondían, en mayor o menor medida, a los dictados de la cúpula romana. El arquitecto Manlio Costa (1901-1936), junto a Marinetti (18761944) y al pintor -y arquitecto de formación- Enrico Prampolini (1894-1956), visitaron la estructura en 1933 reclamándola como otro de los logros de la arquitectura futurista en un periodo en que la vanguardia italiana producía más teoría arquitectónica que edificios propiamente dichos.

Ese distanciamiento, proscripción -recordémoslo- en palabras de De Seta, se observa igualmente en trabajos como el Edificio de Correos de Agriento (1932-34), el edificio Postal y Telegráfico de Latina (1932), el Edificio de Correos de Pola (1932-33), el Postal y Telegráfico de Sabaudia (1933-34), la estación de Siena (1931-35), Trento (1934-36) y las terminales de Montecatini y Reggio Calabria (1937). Quizá sea en Montecatini donde ese espíritu de desplazamiento se refleja en mayor medida. Oriol Bohigas (1925) ha definido la terminal como el edificio más puramente wrightiano de Italia. Su diseño integral, así como la falta de un estilo definido, remite a la ausencia sugerida en la plástica metafísica, lo que configura una mirada al pasado que irrumpe, de manera concluyente, para constituir un presente detenido, congelado en el tiempo indefinidamente.

2 FORTI, A., "Dall'Alpi alle Piramidi" en VV. AA., Angiolo Mazzoni (1894-1979). Architetto nell'Italia tra le due guerre, Bolonia, Galleria Comunale d'Arte Moderna, 1984, p. 32. 


\section{¿UN ARQUITECTO FUTURISTA? LA ESTACIÓN DE SANTA MARÍA NOVELLA}

Angiolo Mazzoni fue uno de los arquitectos más heterodoxos de los que se adhirieron al futurismo, aunque el movimiento vanguardista, en lo que se refiere a esta disciplina, no tuvo un programa concreto sino más bien distintas aporta-ciones individuales que fueron construyendo irregularmente su relato. Contra-riamente a la mayoría de los arquitectos adscritos, los proyectos de Mazzoni fueron construidos y, a diferencia de aquellos que levantaron edificios insustanciales, pabellones efímeros y decoraciones de interiores, edificó con regularidad en su trayectoria italiana. Su obra futurista desembocó en estilos contrapuestos dominando el novecentismo, la metafísica y el racionalismo.

Una constante fue la ilegibilidad para concretar un estilo definido, que se transluce en su obra más relevante, la Central Térmica de Santa María Novella. Un edificio que aún se contempla -con ligeras variaciones debidas fundamentalmente a intervenciones de mantenimiento y restauración- en la estación florentina. La Central Térmica es un enorme cubo rojo coronado por chimeneas que refleja, por un lado, su adscripción a las tendencias constructivistas y, por otro, el débito a la poética de la primitiva civilización mecánica abanderada por los futuristas, como reseñará posteriormente el teórico británico Reyner Banham (1922-1988), en su relectura megaestructural en los años sesenta.

El proyecto, desde el inicio, estuvo rodeado de polémica. En primer lugar, la adhesión al futurismo de Angiolo Mazzoni obedecía más al interés profesional que a la confluencia estilística y conceptual con el movimiento. Era el momento en el que se había convocado el concurso para la estación de Santa María Novella -adjudicada previamente a Mazzoni por encargo de la Dirección General de la Ferrovie dello Stato- pero la polémica que había levantado el proyecto del arquitecto boloñés -"La Nazione", LXXIV, 20 de febrero de 1932-, llevó a los responsables estatales a convocarlo públicamente.

Una de las reacciones más violentas contra el proyecto inicial de Mazzoni fue la del propio F. T. Marinetti que, junto al escultor Ernesto Thayhat (18931959), firmó una carta de protesta -"La Nazione", LXXIV, 23 de julio de 1932-. Marinetti, como Académico de Italia, junto a otros destacados miembros del panorama cultural italiano, constituyeron el 28 de julio el jurado del concurso presidido por Cesare Oddone (1865-1941), ex director General de la Ferrovie dello Stato, además de Marcelo Piacentini, Armando Brasini (1879-1965), Cesare Bazzani (1873-1939), Ugo Ojetti (1871-1946) y el escultor Romano Romanelli (1882-1969). 
Este fue el interés principal que vinculó a Mazzoni con el movimiento marinettiano. Pero la inclinación, desde luego, no era unilateral. El pope futu-rista estaba empeñado en contemplar construcciones futuristas que no tuvieran carácter transitorio y observó en la figura de Mazzoni el instrumento para cumplir su deseo, el de una arquitectura que, como teorizaron en los manifiestos de los años heroicos, pudiera desafiar a los siglos a través de edificios que cumplieran los condicionantes de la arquitectura futurista.

El arquitecto no sólo se benefició de un trato de favor en cuanto al concurso, así como de otras adjudicaciones posteriores, sino que se convirtió en el arquitecto oficial del futurismo. Y ello, pese a perder el concurso de la estación de Florencia -aunque se quedó con el premio de consolación que suponía la Central Térmica-, cuyo proyecto tenía mucho más interés arquitectónico que el diseño tradicionalista que había presentado para la estación.

Angiolo Mazzoni se había unido al futurismo con una declaración de intereses dirigida a Marinetti y publicada el 14 de mayo de 1933 en la portada de "Futurismo" (L'architetto Angiolo Mazzoni aderisce al movimiento futurista. L'adesione di Mazzoni e la risposta di Marinetti): "Materialmente entro ahora en el futurismo. Moralmente pertenecía a este movimiento desde mil novecientos quince, cuando pensándolo, me autoproclamé seguidor de Sant'Elia"'3. Conocedor de las tendencias que comenzaban a imponerse, exponía los problemas del futurismo y el racionalismo como si se tratara de una misma problemática: "racionalismo - escribe- es entretanto una parte del futurismo"4.

El 18 de diciembre de 1932, Marinetti asistió a la inauguración de la Ricevitoria Postelegrafica y la Estación de Littoria proyectadas por Mazzoni. Al día siguiente, sobre las páginas de la "Gazzetta del Popolo" en el artículo Ritmo heroico, defendió su trabajo como: "grandes y altas celosías semicilíndricas de defensa contra las epidemias de malaria y superación futurista de la simple racionalidad".

Marinetti observaba edificios nuevos, diferentes -futuristas según su criterio de apropiación de todo lo que apuntara a modernidad-, y pensó que el arquitecto boloñés era adecuado para dirigir la disciplina dentro del movimiento. Mazzoni, como se había reseñado anteriormente en los manifiestos canónicos de la arquitectura futurista, empleó diversos materiales de construcción, consiguiendo singularidades estilísticas y constructivas que seguían los parámetros teorizados por los futuristas de los años diez, aunque declinando en una

3 MAZZONI, A., "L'architetto Angiolo Mazzoni aderisce al movimiento futurista. L'adesione di Mazzoni e la risposta di Marinetti" en Futurismo a. II, n 36, Roma 1933, p. 1.

4 CRISPOLTI, E., Ricostruzione Futurista dell'Universo, Turín, Museo Civici, 1980, p. 481. 
amalgama de estilos con reminiscencias tradicionalistas. De ahí que aparezcan conclusiones clásicas en Grosseto y Palermo, la influencia constructivista soviética de la Central Térmica de Florencia, los modelos de Ragusa y Foggia, situados entre el racionalismo y el expresionismo, las estaciones de Trento, Brennero y Reggio Calabria de carácter racionalista y la inspiración centroeuropea de Bérgamo y Varese. El funcionalismo aparece en Latina, el edificio de Ostia Lido, Sabaudia, Siena y Montecatini así como volúmenes añadidos en Santa Lucía de Venecia y Messina buscando equilibrio con el entorno. Todos ellos muestran una serie de influencias arquitectónicas que no eran afines a las propuestas futuristas -cuyo único ejemplo bien definido lo encontramos en los interiores que diseñó Fortunato Depero (1892-1960) para el edificio de correos de Ferrara y algunas de las lámparas proyectadas en los edificios de Massa y Bérgamo-.

La pertenencia de Mazzoni al grupo vanguardista levantó recelo tanto en la cúpula como en los grupos futuristas autónomos -grupos de iniciativa provinciales que operaban de manera independiente a los dictados centralistas de Marinetti colaborando, en algunos casos, con artistas y arquitectos que no tenían relación alguna con los vanguardistas- que lo consideraban un arquitecto sin motivación e interés, por lo que hubo una coexistencia problemática antes, durante y después de su adhesión al futurismo.

Un rechazo que, por otra parte, se extendía fuera del movimiento. El futurismo levantaba ampollas entre algunos racionalistas y teóricos de la arqui-tectura que lo consideraban un simple instrumento propagandístico. Giuseppe Pagano (1896-1945), director de "Casabella", ironizaba sobre la adjudicación de la Central Térmica como un empeño personal del Ministro de Comunicación Constanzo Ciano di Cortelazzo (1876-1939). Consideraba que el edificio era una excusa para que el arquitecto demostrara que era capaz de hacer un proyecto racionalista. Las afirmaciones de Pagano iban a crear polémica entre "Casabella" y el periódico "Sant'Elia", órgano oficial del futurismo romano.

Tras la polémica del proyecto adjudicado a Mazzoni, el 20 de agosto de 1932 se publicó el concurso para la terminal de la estación de trenes de Florencia. Mazzoni escribió dolido a sus superiores por la convocatoria ya que había desarrollado los polémicos bocetos para la estación.

La comisión presidida por Cesare Oddone se reunió los días 15 y 16 de septiembre de 1933 y evaluó los ciento cinco proyectos presentados. Finalmente, el concurso fue adjudicado al Gruppo Toscano formado por Giovanni Michelucci (1891-1990), Italo Gamberini (1907-1990), Nello Baroni (19061958), Piero Berardi (1904-1989), Sarre Guarnieri (1904-1933) y Leonardo 
Lusanna (1908-1973) -pertenecientes a los florentinos Grupos Futuristas de Iniciativa de Antonio Marasco (1896-1975)-, lo que avivó la polémica entre defensores del primer proyecto y los que lo habían fustigado hasta el momento.

Algunos futuristas saludaron entusiasmados el proyecto del Gruppo Toscano en "Futurismo", el 20 de febrero de 1933 con el artículo: "La vittoria di Sant'Elia. Il progetto del Gruppo Toscano premiato nel concorso per la nuova stazione di Firenze è netanmente futurista. Conclusione sulla polemica sulla architettura". Por el contrario, el 16 de abril de 1933, el director de "Futurismo", el judío y fascista Mino Somenzi (1899-1948) escribió "Precisando", que criticaba la decisión del jurado y se alejaba de los preceptos de F. T. Marinetti, que se había expresado a favor del proyecto de Gruppo Toscano, para que el proyecto inicial de Mazzoni no se llevara a cabo 5 .

El 14 de marzo Giuseppe Pagano escribió a Mazzoni pidiéndole cortésmente que apoyara el proyecto vencedor para concluir la polémica. Mazzoni le telegrafíó su negativa amparándose en la imparcialidad de su condición de funcionario. A medidos de marzo en "Casabella" apareció el artículo La nuova stazione di Firenze, en el que Pagano acusó la escasa transparencia y los medios poco lícitos en la adjudicación primera de la obra, así como a la condición de funcionario estatal de Mazzoni,

También este concurso tenía una cierta tendencia a ser un botín fácil para un funcionario de la ferroviaria. El concurso carecía de muchos datos esenciales para una conclusión bien fundada (falta gravísima de las cotas de nivel) -debido sobre todo a la difícil topografía donde, en su momento se debía erigir la estación, un complejo verdaderamente impresionante pare ese momento-. Estas informaciones podía tenerlas exactas solamente un funcionario concurrente.

En el número de agosto/septiembre "Casabella" publicó un artículo de Pagano con el título "Un nuovo architetto futurista?", donde ironizaba su polémica adhesión al movimiento futurista:

Parece que el inventor de la torre del campanario de la estación de Santa María Novella haya superado con cien alabanzas los exámenes de arquitecto futurista sea señalado como -el más preparado para resolver el complicado y costoso problema de la renovación de los edificios públicos en Italia-. Hace seis meses rechazaba por escrito participar en nuestra defensa para defender el proyecto premiado para la estación de Florencia.

5 SOMENZI, M., "Precisando" en Futurismo, a. II, n 32, Roma, 1933, p. 6. 
El 22 de octubre "Sant'Elia" n'. 2 a. I, en el artículo Veleno e malincolia se defiende a Angiolo Mazzoni de los ataques de "Casabella". "Casabella", en noviembre de 1933, contestó a las alusiones de los futuristas, que recibieron contrarréplica el 1 de enero de 1934 en "Sant'Elia", no. 1, a. II. Pese al intercambio dialéctico, Pagano no se equivocaba sobre las intenciones de Angiolo Mazzoni en relación con los futuristas. Uno de los miembros del Gruppo Toscano, Italo Gamberini, fue un personaje fundamental en la polémica ya que defendió su tesis de licenciatura el 26 de noviembre de 1932. Esta lectura contenía gran parte del proyecto que presentaría a concurso para la estación de Florencia el Gruppo Toscano.

En el último diseño presentado por Mazzoni para el concurso destacó la opinión del crítico Roberto Papini (1883-1957). Papini, profesor, historiador de arte y consultor honorario de la Ferrovie dello Stato, convenció a Mazzoni de que presentara otro proyecto, el tercero, que no tuviera impacto ambiental con respecto al ábside de Santa María Novella y que se integrara en el su contexto arquitectónico. El proyecto definitivo, "La nuova stazione ferroviaria si Santa Maria Novella”, apareció publicado en "La Nazione” el 20 de febrero de 1932. Pero Mazzoni, no tuvo la lucidez que sí tuvo el Gruppo Toscano "la de que el proyecto no sería obtenido por asonancia formal sino por consonancia estructural".

Mazzoni, como señaló Pier Maria Bardi (1900-1999), no propuso analogías, sino una mimesis entre los dos edificios. Posteriormente, por indicación de Papini, eliminó la torre de la fachada de la estación, lo que la convertía en otra iglesia formalmente dispuesta frente a la antigua iglesia concluida por Vasari. Su proyecto -el $33 \mathrm{C}$ - era, finalmente, un híbrido desfasado. Mazzoni probablemente no debió haber atendido tantas influencias historicistas en su trabajo, que no solo no lo clarificaron, sino que lo confundieron, haciendo que finalmente perdiera un proyecto que previamente le había sido adjudicado y que los sectores más progresistas calificarían irónicamente como el esquema de un cementerio ${ }^{7}$.

6 KOENING, G. K., "Due note sul desing di Angiolo Mazzoni” en VV.AA., op. cit., p. 17.

7 SEVERATI, C., "Angiolo Mazzoni. Siena'33. Un architetto futurista?" en L'Architettura, Cronache e Storia, XX, n² 234, 1975, p. 786. 


\section{LA CENTRAL TÉRMICA DE SANTA MARIA NOVELLA}

La Central Térmica que se ubica junto a las oficinas de correos de la calle Alemanni y la de Squadra Rialzo, era la primera parte del proyecto de Mazzoni para el plan definitivo de la estación de Florencia. Fue proyectada con los técnicos arquitectónicos de la Ferrovie dello Stato, entre los cuales colaboraba un jovencísimo Pier Luigi Nervi (1891-1979) como consultor estructural.

La Central Térmica ha tenido una suerte historiográfica dispar. En primer lugar, por las polémicas de Mazzoni, luego por las injustificadas críticas de Giuseppe Pagano y, finalmente, por los ataques de los enemigos acérrimos del arquitecto que han ensombrecido un proyecto arquitectónico que, para la Italia del momento, marcaba una senda de progreso, una posibilidad diferente de aplicación racionalista con influencia constructivista. Este giro racionalista justificaba una de las máximas de Mazzoni respecto al futurismo explicando que: "solo partiendo de las fuentes puras del futurismo, el racionalismo que es su hijo, podrá encontrar su salvación y su razón de ser"8.

Hasta hace apenas tres décadas, no se ha elaborado una lectura coherente de esta edificación. Ningún estudioso ni crítico de ese momento, si exceptuamos a Pier Maria Bardi, se ha interesado por ella. Bardi sabía que Pagano se había aliado con Piacentini -del que era enemigo, e ironías del destino, ocho años antes había ganado el segundo premio de la Sociedad de Naciones con un proyecto realizado en colaboración con Mazzoni- para formar la comisión antimazzoniana en el proceso del concurso de la estación florentina.

El proyecto de la Central Térmica de Santa Maria Novella, aprobado el 9 de febrero de 1932, era una excepción, no sólo de la genealogía arquitectónica de Mazzoni, sino en el panorama europeo. La central se ha definido de manera concluyente como constructivista, y la similitud con el proyecto, desde la primera fase a la ejecución, obedeció a un sinnúmero de modificaciones. Mazzoni conocía bien la vanguardia rusa y el constructivismo través de las ediciones Morancé, textos italianos especializados de arquitectura de los años treinta y sus primeros diseños obedecieron a esa influencia.

El edificio, por otra parte, obedecía el desarrollo tecnológico como organismo integral, cuya referencia no funcionalista a la estructura exterior eran las ventanas con ciertas resonancias mendelsohnnianas. Una construcción que renegaba del vapor para incluirse en la denominada divina luz eléctrica, que

8 MAZZONI, A., en VV.AA., op. cit., p. 11. 
habían apuntado los futuristas en sus primeros relatos de 1909 y que se instituyó en el país transalpino con la aparición de los electrotrenes en 1936.

El color del edificio, de un rojo intenso, era el contrapunto a la suciedad provocada por la polución de las locomotoras. Cuatro chimeneas que, conectadas con los pisos de los trabajadores por una pasarela, se unirían a una escalera de caracol, creando un signo de corte constructivista. En la ejecución final de la obra, la estructura fue simplificada, eliminando los caballetes y convirtiendo en cilíndricos los caminos. La tensión expresiva derivó hacia el racionalismo, perdiendo alguna de sus características constructivistas más reseñables de influencia alemana e inglesa.

Cuando fue construida, la Central Térmica de Santa Maria Novella fue atacada incluso por sectores políticos. De este modo, Francesco Giunta (18871971), en una pregunta al ministro Galeazzo Ciano Sr. (1903-1944), habría criticado "el horrible barracón pintado de rojo"9 que el viajero encontraba en la entrada de la estación de Florencia.

Roberto Papini sostenía que una central térmica no era una arquitectura, como no lo era la Einsteinturm (Torre Einstein, 1924) de Erich Mendelsohn, puesto que habían perdido sus cualidades de edificación para convertirse en máquinas y no en construcciones civiles. Éstas obedecían a leyes compositivas distintas, en las que el hombre no era el protagonista -al perder su referencia-, sino que el verdadero centro era la máquina, elemento esencial y núcleo de la imagen. Opina Giovanni Klaus Koenig: "Si no era arquitectura, la Central Térmica de Mazzoni podría ser cualquier cosa, desde el momento en el cual existía. Y hoy sabemos finalmente lo que es: un colosal -en todos los sentidos- pedazo de diseño industrial".

\section{EL MANIFIESTO FUTURISTA DE LA ARQUITECTURA AÉREA}

En 1934 apareció en "Sant'Elia" el Manifiesto Futurista de la Arquitectura Aérea firmado por Marinetti, Angiolo Mazzoni y el periodista Mino Somenzi, director de la revista y uno de los más activos miembros del movimiento, autodefinido en el texto como periodista aeronáutico. Los años treinta fueron una época de ajuste con el progreso tecnológico y de acondicionamiento político, en el que el grupo actuaba con cierta independencia del dictado fascista, pero siempre bajo una vigilancia que no permitía la libertad con la que actuaban antes de la Primera Guerra Mundial. Una vez que las pretéritas máquinas ensalzadas en

9 GIUNTA, F. en KOENING, G. K. en VV.AA., op. cit., p. 16. 
los textos y manifestaciones artísticas de los años diez habían desaparecido, había que buscar nuevas lecturas de la modernidad. Por ello, los futuristas comenzaron a ensalzar las posibilidades artísticas establecidas por el cambio sensorial producido por la velocidad de los aeroplanos. Este manifiesto, como extensión de su política artística, defendía que la aviación modificaba la experiencia urbana, lo que debería llevar a la concepción de una nueva arquitectura proponiendo la creación de una ciudad compuesta de tres líneas paralelas.

En los tejados de esa la ciudad aterrizarían los aeroplanos siendo, a la vez, fachada de la ciudad -diseñada para ser vista exclusivamente desde el aire-. Estas ciudades se extenderían a través de toda la península italiana separadas por cincuenta kilómetros y donde sólo habría estaciones de servicio para los aeroplanos. Estas teorías, a su vez, eran una reevaluación de proyectos clásicos de la genealogía arquitectónica futurista tales como la Estación para aeroplanos y trenes con funiculares y ascensores sobre tres niveles de calles (1914) y Estación para aeroplanos y trenes (1914) de Antonio Sant'Elia (1888-1916), Ejemplo de adaptación futurista a una estructura previa (1919) y Ciudad superior (1931) e Hidropuerto y casas (1931) de Virgilio Marchi (1895-1960) y Aeroestación-hotel (1930) Estación marítima, aérea, ferroviaria (1930) y Aeroestación (1931) de Tulio Crali (1910-2000) entre otras.

En la ciudad aérea desaparecerían las leyes clásicas de la concepción arquitectónica. No habría una estética definida y cualquier estructura tendría carácter propio bajo un único principio dominante establecido por los expendedores de combustible. Las casas se adaptarían al gusto de los propietarios y, finalmente, se crearía un ambiente artificial para que siempre estuvieran iluminadas. Los periodos de sueño de sus habitantes se deberían -en sus palabrasdistribuir científicamente.

Como había marcado las líneas editoriales de "Futurismo" y posteriormente "Sant'Elia", existe, por parte de Mazzoni, una preocupación por la utilización de materiales contemporáneos y modernos que se traslada en el manifiesto. La ciudad única tendría los elementos simbólicos que reflejarían la personalidad de la Italia de Mussolini,

Volando de noche, con los soles apagados, las tendremos debajo de nosotros como relucientes vías lácteas sembradas de las estrellas creadas por la quieta explosión de las letras resplandecientes de esta palabra que abarca de los Alpes hasta Mogadiscio.

En este manifiesto no sólo se ensalzaban las novedades de la arquitectura futurista, sino que también se vanagloriaban otras realizaciones como el edificio Lingotto de Fiat en Turín -actualmente sede y museo de la compañía- construido 
por Giacomo Matté-Trucco (1869-1934) que, si bien no estaba en contacto con los futuristas, tenía ciertas reminiscencias teóricas del grupo vanguardista con la inclusión de un tejado que incluía una pista de pruebas automovilistas.

La ciudad, en este sentido, se convertía en un proyecto estético. Las aeropistas estarían coloreadas para hacerse visibles. Su forma se adecuaría a una estructura que pudiera defenderse de un ataque, además camuflar a los aviones y submarinos, que también se adaptarían a las características estéticas de la nueva ciudad.

Después de la aparición del manifiesto, surgió desde "Sant'Elia" la idea de convocar un concurso para desarrollar proyectos arquitectónicos con esta temática. Nada más se sabe del mismo, solo que hubo dos dibujos de La città única a linee continue (1934) presentados por Mino Somenzi y Fernando Spiridiglozzi, firmados como (Minos-Spiri), siendo publicados en el "Sant'Elia" $n^{\circ} 4$, del 15 de febrero de 1934. En los mismos aparecían representados el sector civil, el comercial, el industrial y el deportivo. En el subsuelo estarían ubicadas las estaciones neumáticas. Los edificios tendrían grandes hileras de ascensores, jardines colgantes, así como aeropuertos turísticos.

\section{CÍRCULOS ABIERTOS: RELECTURAS POSTMODERNAS DEL CAPITA- LISMO TRIUNFANTE}

Si iniciábamos este artículo mencionando el reflejo de la cultura arquitectonica en la producción cinematográfica de los sesenta y setenta en Italia, es necesario volver a detenernos en ese punto. Películas actuales que han revisado y resituado las arquitecturas de los años treinta como L'ultimo bacio (El último beso, 2001) y Baciami ancora (Bésame otra vez, 2010) de Gabriele Muccino y Manuale d'amore (Manual de amor, Giovanni Veronesi, 2005) son comedias románticas de éxito que han adaptado -y disuelto- el mensaje arquitectónico más allá de los significados que contiene. Quizá haya sido la directora Julie Taymor (1952) quien haya impregnado de totalitarismo estético su excesiva y brutal Titus (id., 2001) en que la arquitectura es, a su vez, protagonista y parte de la historia. A partir de su débito con el teatro y la ópera, Titus se configura como una extensión postmoderna de Il Conformista de Bertolucci, esta vez utilizando el clasicismo de la obra Shakespeare ante la actualidad que ofrecía el texto de Alberto Moravia (1907-1990). Titus nos redirige, por otra parte, al comercial de Nike, "The Mission" rodado en el archiconocido Palazzo della Civiltà Italiana (Giovanni Guerrini, 1939), quizá la estructura que mejor defina la politización estética de la época. Estrenado en marzo de 2000, la arquitectura del silencio del EUR42, representó el emblema de la actitud de la compañía 
deportiva. Por otra parte, en 2013, el "coliseo cuadrado", se convirtió en la sede mundial del gigante de la moda Fendi-Arnault, que alquiló la totalidad del edificio para oficinas y salas de exposiciones por dos millones ochocientos mil euros al año durante tres lustros.

La arquitectura de la postmodernidad había recuperado previamente ese discurso, reasumiendo los postulados de la vanguardia, especialmente de la metafísica y el futurismo. Podemos considerar, de este modo, los dibujos utópicos del arquitecto Massimo Scolari (1943), en los que las poéticas de la vanguardia se convierten en iconos que generan un universo particular que rememora periodos pretéritos y que, como las obras en las que están basadas, van más allá del espacio y el tiempo. Igualmente, la última producción de Aldo Rossi (19311997) se alinea en esa dimensión, la de una praxis que se alimenta del pasado para convertirse en imagen del presente. El Complesso Uffici Disney Development Company (1991-1996) desarrollado junto a Morris Adjmi (1959), jefe en ese periodo de su oficina en Nueva York, se basaba en la historia de las piazze italianas históricas - esas plazas incendiadas por el sol de mediodía que inspiraban la pintura y el pensamiento dechiriquianos- así como en las plazas sin un estilo definido de las nuevas ciudades norteamericanas. Rossi, como otros arquitectos postmodernos, se convirtió en la imagen arquitectónica de Disney, la mayor corporación mundial del entretenimiento, auspiciada por el presidente Michael Eisner (1942), tematizando la arquitectura más allá de cualquier discurso crítico.

Por lo tanto, es necesario revisitar el trabajo de los arquitectos que estuvieron al servicio del poder en los años treinta como Angiolo Mazzoni, heterodoxo arquitecto futurista, ingeniero sin estilo, cuyo trabajo marcó tendencia en una época en la que la represión y el silencio, así como los instantes detenidos en el infinito, se convirtieron en una metáfora de la época. Esas lecciones, reasumidas y reacondicionadas, han tendido un efecto perverso en algunos discursos arquitectónicos de la postmodernidad, en las que la arquitectura se convirtió, en palabras de Juan Antonio Ramírez, en un espacio de representación del capitalismo triunfante. Su lectura, transustanciada, es similar. Quizá su extraordinaria presencia sea suficiente para embelesarnos, pero siempre desconfiando del discurso hegemónico propuesto. 


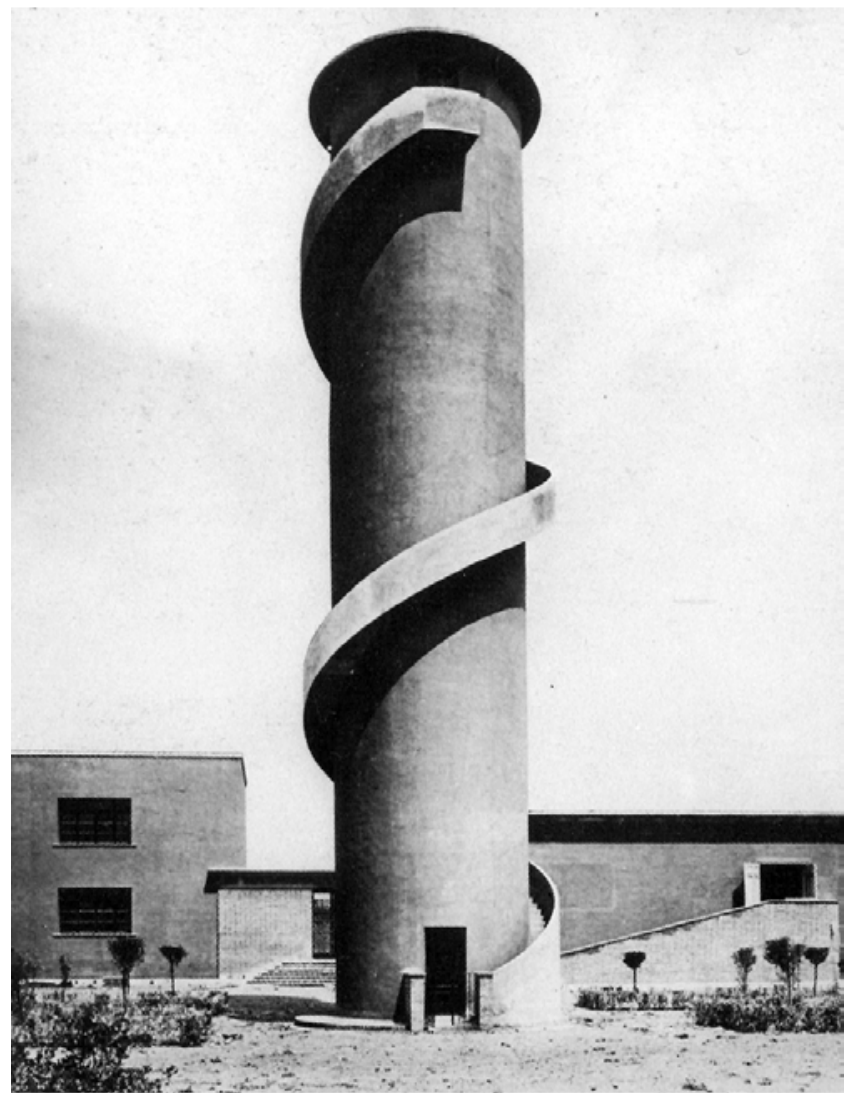

Figura 1. Angiolo Mazzoni, Serbatoio dell'acqua (Depósito del agua) Colonia Rosa Maltoni Mussolini, Calambrone, 1933. 


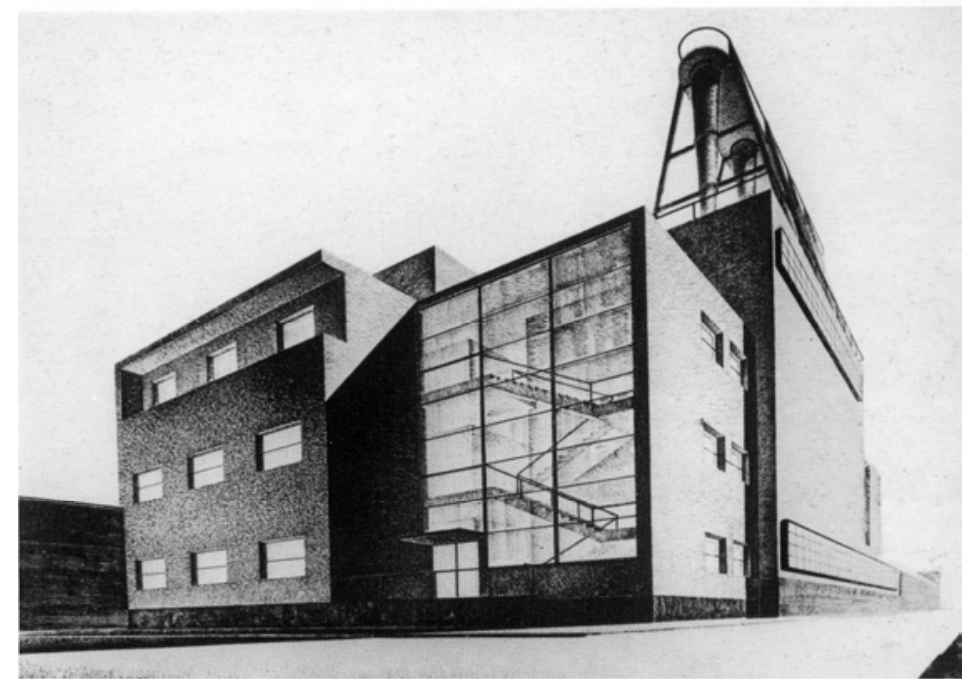

Figura 2. Central Térmica de Santa María Novella, Florencia. Perspectiva sobre Via Citadella (1932).

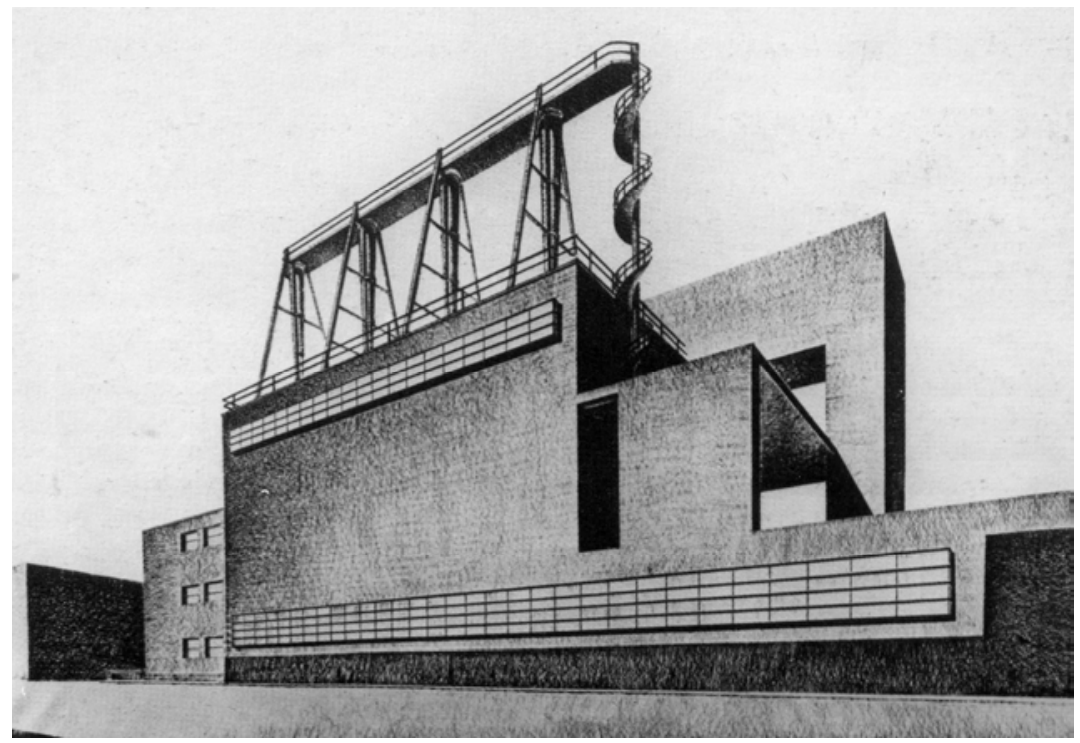

Figura 3. Central Térmica de Santa María Novella, Florencia. Perspectiva sobre Via delle Ghiacciaie (1932) 


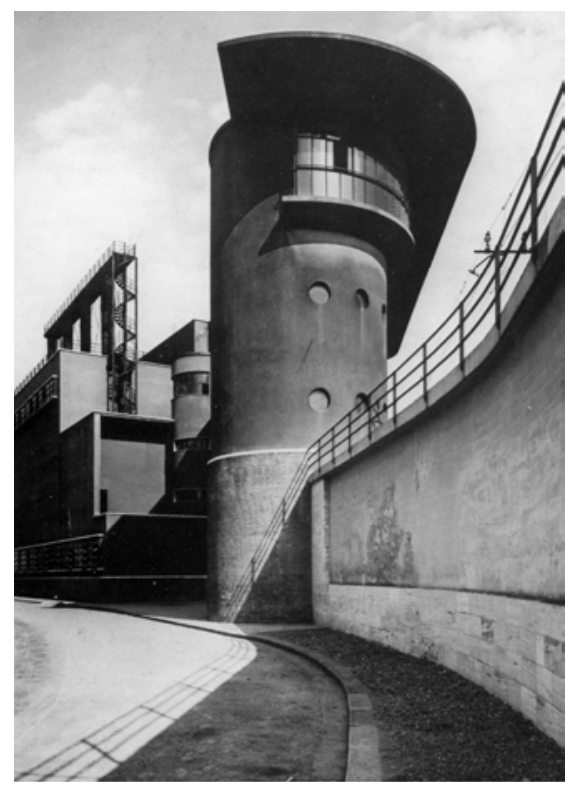

Figura 4. Central Térmica de Santa María Novella, Florencia. Perspectiva sudeste. Fotografía de la época.

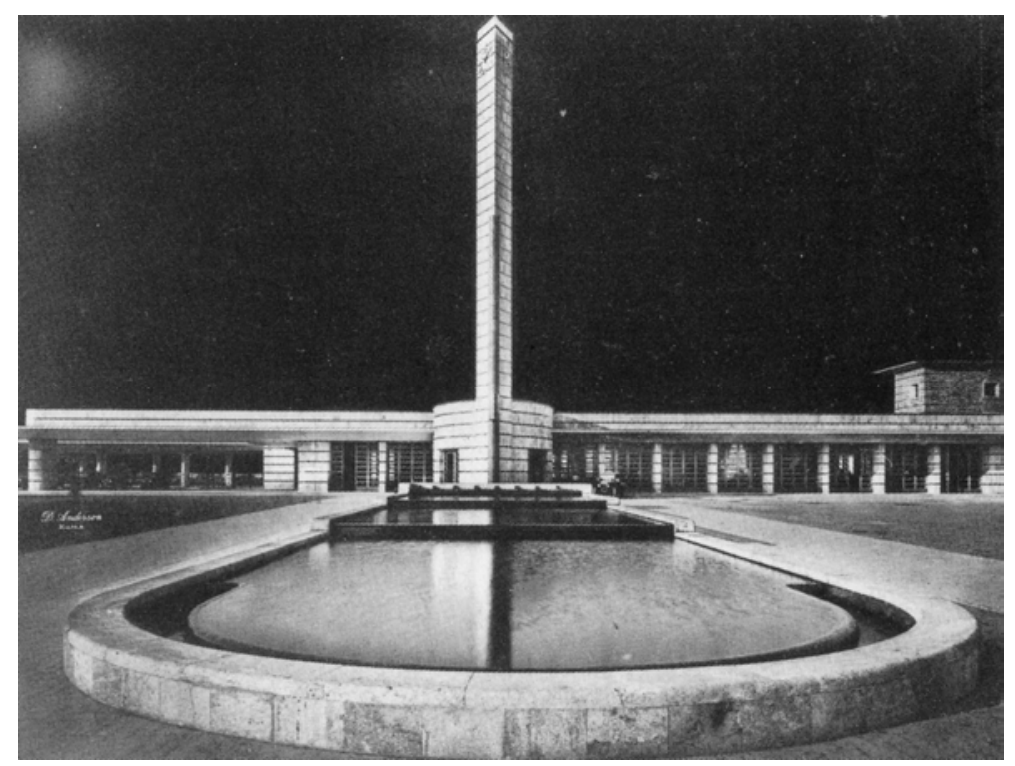

Figura 5. Estación de Montecatini (1937). 


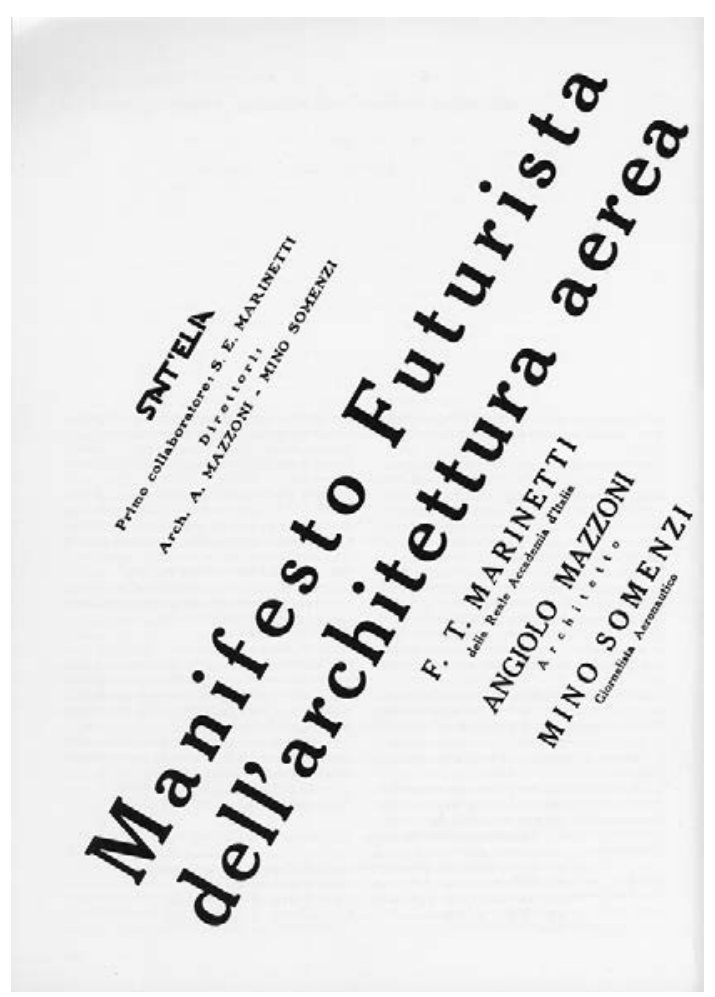

Figura 6. F.T. Marinetti, Angiolo Mazzoni y Mino Somenzi, Manifiesto futurista de la arquitectura aérea (1934).

Juan Agustín Mancebo Roca

Departamento de Historia del Arte Facultad de Humanidades de Albacete Universidad de Castilla- La Mancha Campus Universitario $\mathrm{s} / \mathrm{n}$ 02071 Albacete (España) https://orcid.org/0000-0003-4942-8879 Juan.Mancebo@uclm.es 